\title{
Ultrasonic assessment of liver stiffness and carotid artery elasticity in patients with chronic viral hepatitis
}

\author{
Jing-Hua Li ${ }^{\dagger}$, Ning Zhu ${ }^{\dagger}$, Ying-Bin Min, Xiang-Zhou Shi, Yun-You Duan and Yi-Lin Yang ${ }^{*}$
}

\begin{abstract}
Background: This study investigated the relationship between liver stiffness and carotid artery elasticity in patients with chronic viral hepatitis. We used an acoustic radiation force impulse (ARFI) technique to measure stiffness, and a radio frequency (RF) vascular quantitative ultrasound technique to measure changes in common carotid artery elasticity and vascular function.
\end{abstract}

Methods: Two-hundred seventeen patients with chronic viral hepatitis caused by either hepatitis B virus (HBV) or hepatitis $\mathrm{C}$ virus ( $\mathrm{HCV}$ ) were enrolled. We divided the patients into two groups, one comprising 147 patients with chronic hepatitis B (CHB) (98 men and 49 women, average age $46.5 \pm 12.2$ years) and another comprising 70 patients with chronic hepatitis C (CHC) (47 men and 23 women, average age 47.6 12.1 years). Additionally, 64 healthy ageand sex-matched participants (43 men and 21 women, average age $47.8 \pm 5.1$ years) were selected as the control group. The ARFI technique was used to measure liver stiffness and the RF ultrasound technique was used to measure carotid artery elasticity parameters including intima-media thickness (IMT), pulse wave velocity (PWV), arterial wall dilation coefficient (DC), compliance coefficient (CC), sclerosis indices a and $\beta$, and augmentation index (Aix). Clinical indicators, liver stiffness, and carotid artery elasticity parameters were observed and compared between the different age groups to investigate the correlation between carotid artery elasticity parameters and liver stiffness.

Results: The ARFI values for the CHB and CHC groups were significantly higher than those for the control group (1.84 \pm 0.52 vs. $1.04 \pm 0.11 \mathrm{~m} / \mathrm{s} ; 1.86 \pm 0.37$ vs. $1.04 \pm 0.11 \mathrm{~m} / \mathrm{s}$, respectively; $P<0.001)$. When compared to the control group, both $\mathrm{CHB}$ and $\mathrm{CHC}$ groups showed an IMT of the same order, but had significantly higher elasticity parameters, such as $a$ and $\beta$, as well as lower DC and CC values $(P<0.001)$. The PW of the CHC group was significantly higher than that of the control group ( $7.98 \pm 1.42$ vs. $6.09 \pm 0.90 \mathrm{~m} / \mathrm{s}, P<0.001)$. In the CHB group, all parameters including ARFI, IMT, PWV, DC, CC, $a$ and $\beta$, were significantly different between the two age groups $(P<0.05)$. Within the CHC group, all parameters including IMT, PWV, DC, a and $\beta$, were significantly different between the two age groups $(P<0.05)$, except for ARFI, wherein the difference was not statistically significant. The correlation analysis and stepwise multiple linear regression analysis indicated that for patients with $\mathrm{CHB}$, age was an independent predictor of common carotid artery IMT ( $R^{2}=0.468, F=54.635$, and $\left.P<0.001\right)$. For patients with $C H C$, age and blood sugar were independent predictors of common carotid artery IMT ( $R^{2}=0.465, F=29.118$, and $\left.P<0.001\right)$.

Conclusion: Although based on ARFI and RF ultrasound, the carotid artery IMT in patients with CHB and CHC was not significantly higher than that in the control group, their functional elasticity parameters had already changed. This finding serves as a useful reference for the clinical diagnosis of vascular diseases in patients with viral hepatitis.

Trial registration: ClinicalTrials: ChiCTR1800015859 25/04/2018.

Keywords: Ultrasound, HBV, HCV, Carotid artery elasticity

\footnotetext{
* Correspondence: yangyl66@126.com

†Jing-Hua Li and Ning Zhu contributed equally to this work.

Department of Ultrasound Diagnosis, Tangdu Hospital, Fourth Military

Medical University, Xi'an 710038, Shaanxi Province, China
}

(c) The Author(s). 2018 Open Access This article is distributed under the terms of the Creative Commons Attribution 4.0 International License (http://creativecommons.org/licenses/by/4.0/), which permits unrestricted use, distribution, and reproduction in any medium, provided you give appropriate credit to the original author(s) and the source, provide a link to the Creative Commons license, and indicate if changes were made. The Creative Commons Public Domain Dedication waiver (http://creativecommons.org/publicdomain/zero/1.0/) applies to the data made available in this article, unless otherwise stated. 


\section{Background}

Vascular wall elasticity is an important indicator of abnormal lipid metabolism in vascular disease, which is caused by pathogen-mediated chronic liver damage $[1,2]$. Signals in the radio frequency (RF) vascular quantitative ultrasound technique quantify the intima-media thickness (IMT) and arterial stiffness within blood vessels and can serve as a sensitive indicator of early changes in vascular wall stiffness. The progression of liver fibrosis changes liver morphology and hepatic haemodynamics and decreases liver function. Liver biopsy has been the gold standard to measure and classify liver fibrosis, but because of its invasiveness, its clinical use is limited. Recently, elastography, a novel non-invasive technique for evaluating the degree of liver fibrosis, has gradually been applied in clinical practice and has been included in several liver disease diagnosis and treatment guidelines [3]. Preliminary experiments found that carotid artery elasticity parameters in patients with coronary artery disease and diabetes differed from those of healthy subjects [4]. However, whether these parameters were correlated with the degree of liver fibrosis in patients with chronic viral hepatitis have not been not studied using the new vascular measurement technologies. As a result, we conducted relevant clinical investigations and experiments to understand the extent of the changes in carotid artery morphology and function in patients with chronic viral hepatitis. These findings would help to determine whether the liver fibrosis is related to macrovascular diseases.

\section{Methods}

\section{Research targets and grouping}

A total of 217 consecutive patients with chronic viral hepatitis that were treated at our hospital between December 2015 and March 2017 were enrolled. The study population comprised 147 patients with Chronic hepatitis $\mathrm{B}(\mathrm{CHB})$ and 70 patients with Chronic hepatitis $\mathrm{C}(\mathrm{CHC})$. Patients were admitted into the $\mathrm{CHB}$ group according to the standard chronic hepatitis B diagnostic criteria [5], defined as hepatitis B surface antigen-positive without detectable ascites. Decompensated patients with symptoms such as ascites and lower oesophageal varices were excluded from this group. In the CHB group, there were 98 men and 49 women, with an average age of $46.5 \pm 12.2$ years. Among them, 34 patients had biopsy-proven liver fibrosis. Patients enrolled in the $\mathrm{CHC}$ group were hepatitis $\mathrm{C}$ virus antibody- (HCVAb) positive and had decompensated liver function. The exclusion criteria for the $\mathrm{CHC}$ group were the same as those for the $\mathrm{CHB}$ group. The $\mathrm{CHC}$ group consisted of 47 men and 23 women, with an average age of $47.6 \pm 12.1$ years. Among them, a biopsy confirmed liver fibroses in 21 patients. Contemporaneously, 64 healthy subjects comparable in age and sex, which was defined by no history of liver disease, hepatitis
B virus surface antigen ( $\mathrm{HBsAg}$ ) and HCVAb negativity, normal haemogram, liver, and kidney laboratory examinations, and no detection of liver diseases via 2-D ultrasound examination. Patients with disorders, such as high blood pressure, hypercholesterolemia, and dyslipidemia were excluded. The control group included 43 men and 21 women, with an average age of $45.8 \pm 10.6$ years.

\section{Instruments and methods \\ Liver Elastography ultrasound}

The acoustic radiation force impulse (ARFI) technique uses the $4 \mathrm{C} 1$ convex probe from the Color Doppler Diagnostic Ultrasound Scanner (Siemens, Siemens Acuson S2000) with a frequency of 3.0 to $4.5 \mathrm{MHz}$. During ARFI imaging, measurements were performed with the probe placed between the rib bones with the patient lying in either a dorsal decubitus or left recumbent position, taking normal breaths under a resting state or holding their breath, with displays of real-time 2-D images of the right liver lobe. When the image became clear, the operator used the cursor to locate a $5 \mathrm{~mm} \times 10 \mathrm{~mm}$-sized region of interest that targeted the liver parenchyma area and was free of vessels and bile duct. The measurement depth was fixed at $3 \mathrm{~cm}$. When echoing was uniform within the sampling region, the operator pressed the probe button to freeze the image and display the depth and shear wave velocity (in $\mathrm{m} / \mathrm{s}$ ) in the region of interest. This measurement procedure was repeated 10 times for each patient. The median value of the measurements was recorded as the final result [6] (Fig. 1a).

\section{Quantitative measurement of the common carotid artery}

Measurements of the common carotid artery were obtained using the LA523 vascular probe from the Esaote Mylab Color Doppler Diagnostic Ultrasound Scanner with a frequency of 4 to $13 \mathrm{MHz}$. The ultrasound scanner was equipped with the RF-data technique and the Mylab Desk analysis working station. To take quantitative measurements of the common carotid artery, the patient was placed in the dorsal decubitus position, and instructed to breath normally in a resting state. After the patient's systolic and diastolic blood pressures in the right upper limb were measured, the patient's neck was sufficiently exposed. The ultrasonic probe was moved down longitudinally from the beginning of the common carotid artery, skipping the bifurcation area by $1 \mathrm{~cm}$ and the plaque sites. The operator then moved the sampling frame to the region for measurement, and the scanner automatically recorded the IMT and the elasticity parameters during 6 cardiac cycles. When the standard deviation of the IMT was less than 30, the indicator would turn green, suggesting that the measurements were stable. At that time, the values of parameters such as IMT, pulse wave velocity (PWV), arterial wall dilation 


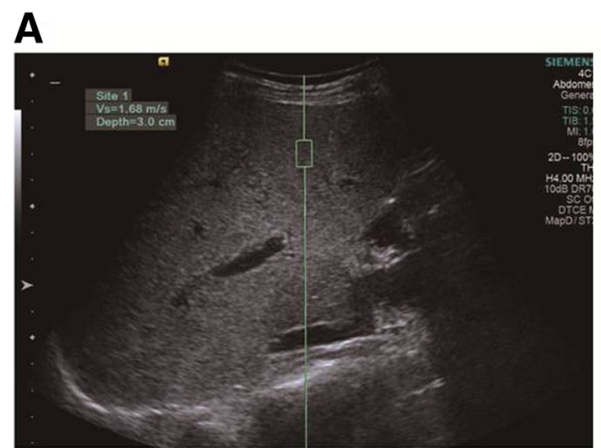

B

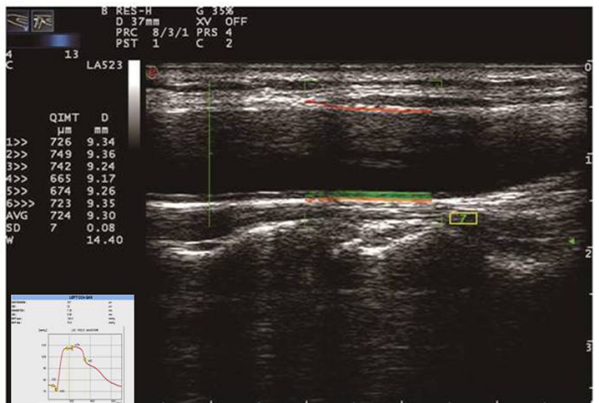

Fig. 1 ARFI liver stiffness images and common carotid artery RF ultrasound images in patients with CHB: a Use of the ARFI technique to measure liver stiffness in patients with CHB using a conventional ultrasound interface. $\mathbf{b}$ Use of QIMT and QAS techniques to quantify the carotid artery intima-media thickness (IMT) and vascular elasticity in patients with $\mathrm{CHB}$

coefficient (DC), arterial wall compliance coefficient (CC), sclerosis indices $\alpha$ and $\beta$, and augmentation index (Aix) were exported as the final results [7] (Fig. 1b).

\section{Clinical information}

For all subjects, the following information was collected: (1) laboratory indicators including blood sugar, glycated haemoglobin, total cholesterol, triglycerides, low-density lipoprotein, high-density lipoprotein, alanine aminotransferase, aspartate aminotransferase, albumin, globulin, and platelets. (2) blood pressures including systolic and diastolic blood pressures.

\section{Statistical analysis}

Statistical analysis was performed using SPSS statistical software (version 19.0, IBM Corp., Armonk, NY, USA). Metrological data were expressed as average \pm standard deviation ( $\bar{X} \pm S$ ), while classification data were expressed as percentages (\%). Inter-group measurement data were compared using one-way analysis of variance (ANOVA) and Levene's homogeneity of variance test. The average values of the two groups of measurement data were compared using the independent sample $t$ test. A determination of correlation was conducted using Pearson's linear correlation method. Casual relationships of various intra-group parameters were investigated using either linear regression analysis or stepwise multiple linear regression analysis.

\section{Results}

\section{General clinical data of the subjects}

General clinical data for all study participants are listed in Table 1. We observed that there was no significant difference in age or sex among the three groups. Compared to the control group, the $\mathrm{CHB}$ group demonstrated a higher blood sugar level $(5.3 \pm 1.1$ vs. $4.9 \pm 0.5$ $\mathrm{mmol} / \mathrm{L} ; P=0.010)$ as well as higher levels of other parameters such as platelets, albumin, AST and ALT, whereas the systolic and diastolic blood pressures were similar. The CHC group demonstrated a higher blood sugar level $(5.3 \pm 1.1$ vs. $4.9 \pm 0.5 \mathrm{mmol} / \mathrm{L}, P<0.001)$, higher glycated haemoglobin level $(6.8 \pm 1.6$ vs. $5.3 \pm$ $0.5 \%, P<0.001$ ), and higher levels of other parameters such as AST, ALT, and platelets compared to the control group. However, there was no significant difference in the cholesterol, triglycerides, HDL, and LDL levels.

\section{Comparison of liver stiffness and elasticity parameters among groups}

Results measured by the ARFI technique showed that both the CHB group $(1.84 \pm 0.52 \mathrm{~m} / \mathrm{s})$ and the $\mathrm{CHC}$ group $(1.86 \pm 0.37 \mathrm{~m} / \mathrm{s})$ had significantly higher liver elasticity parameters than the control group, and the inter-group differences were statistically significant $(\mathrm{F}=$ 90.806, $P<0.001$ ) (Fig. 2a).

Comparison of carotid artery IMT values measured by RF ultrasound showed statistically significant differences $(P=0.015)$ between the control group $(534.08 \pm$ $134.25 \mu \mathrm{m})$, the CHB group $(529.56 \pm 131.04 \mu \mathrm{m})$, and the $\mathrm{CHC}$ group $(587.34 \pm 162.70 \mu \mathrm{m})$. An intergroup comparison showed significant difference between the $\mathrm{CHB}$ and the $\mathrm{CHC}$ group $(P=0.032)$ (Fig. $2 \mathrm{~b})$.

The PWV measurements of the CHC group (7.98 \pm 1.42) were evidently higher than those of the $\mathrm{CHB}$ and the control groups, which were $6.70 \pm 1.32$ and $6.09 \pm$ $0.90 \mathrm{~m} / \mathrm{s}$ respectively. Differences in the intergroup comparisons were statistically significant $(\mathrm{F}=40.310, P<$ 0.001) (Fig. 3a). The $\alpha$ values of the $\mathrm{CHC}$ and the $\mathrm{CHB}$ group were significantly higher than those of the control group, which were $3.03 \pm 0.79,4.13 \pm 1.68$, and $5.77 \pm$ 2.29 , respectively, with statistically significant differences under intergroup comparisons $(\mathrm{F}=44.036, P<0.001)$ (Fig. 3b). Similarly, the $\beta$ values of the $\mathrm{CHC}$ and the $\mathrm{CHB}$ group were significantly higher than those of the control group, which were $6.17 \pm 1.58,8.42 \pm 3.37$, and 
Table 1 General clinical data of all study participants

\begin{tabular}{|c|c|c|c|c|c|}
\hline & & Patients with chron & patitis & $\mathrm{F}$ & $P$ \\
\hline & $\begin{array}{l}\text { Group } \\
n=64\end{array}$ & $\begin{array}{l}\text { Patients with CHB } \\
n=147\end{array}$ & $\begin{array}{l}\text { Patients with } \mathrm{CHC} \\
n=70\end{array}$ & & \\
\hline Age, Years & $45.8 \pm 10.6$ & $46.5 \pm 12.2$ & $47.6 \pm 12.1$ & 0.400 & 0.670 \\
\hline Men Percentage, Count (\%) & $43(67)$ & $98(67)$ & $47(67)$ & - & - \\
\hline Systolic pressure, mmHg & $115.7 \pm 11.6$ & $116.2 \pm 13.1$ & $119.7 \pm 12.8$ & 2.166 & 0.177 \\
\hline Diastolic, pressure mmHg & $71.2 \pm 8.7$ & $73.2 \pm 8.6$ & $71.2 \pm 8.6$ & 1.872 & 0.156 \\
\hline Blood Glu, mmol/L & $4.9 \pm 0.5$ & $5.3 \pm 1.1$ & $6.0 \pm 1.7$ & 15.933 & $<0.001$ \\
\hline Glycated haemoglobin, \% & $5.3 \pm 0.5$ & $5.5 \pm 1.4$ & $6.8 \pm 1.6$ & 30.804 & $<0.001$ \\
\hline $\mathrm{BMl}, \mathrm{Kg} / \mathrm{m}^{2}$ & $23.2 \pm 2.6$ & $23.5 \pm 3.0$ & $24.4 \pm 3.4$ & 2.936 & 0.055 \\
\hline Cholesterol, mmol/L & $3.8 \pm 1.1$ & $3.8 \pm 1.3$ & $3.7 \pm 1.1$ & 0.373 & 0.689 \\
\hline Triglycerides, mmol/L & $1.2 \pm 0.7$ & $1.2 \pm 0.5$ & $1.2 \pm 0.6$ & 0.185 & 0.831 \\
\hline $\mathrm{LDL}, \mathrm{mmol} / \mathrm{L}$ & $1.9 \pm 0.8$ & $1.8 \pm 0.8$ & $1.7 \pm 0.8$ & 0.695 & 0.500 \\
\hline $\mathrm{HDL}, \mathrm{mmol} / \mathrm{L}$ & $1.0 \pm 0.3$ & $1.2 \pm 0.4$ & $1.1 \pm 0.5$ & 3.115 & $0.046^{*}$ \\
\hline Platelets, $10^{9} / \mathrm{L}$ & $187.6 \pm 70.2$ & $137.4 \pm 77.8$ & $138.3 \pm 64.3$ & 11.598 & $<0.001$ \\
\hline AST, U/L & $23.8 \pm 8.7$ & $45.8 \pm 34.2$ & $37.7 \pm 24.6$ & 13.927 & $<0.001$ \\
\hline $\mathrm{ALT}, \mathrm{U} / \mathrm{L}$ & $28.5 \pm 13.8$ & $46.1 \pm 38.5$ & $43.1 \pm 40.4$ & 5.765 & 0.004 \\
\hline Albumin, g/L & $43.8 \pm 7.4$ & $40.9 \pm 8.9$ & $40.8 \pm 8.2$ & 3.104 & $0.046^{*}$ \\
\hline Globulin, g/L & $24.2 \pm 6.3$ & $25.3 \pm 7.2$ & $24.9 \pm 7.1$ & 0.566 & 0.569 \\
\hline
\end{tabular}

Note: $C H B$ chronic hepatitis B, CHC chronic hepatitis C, BMI Body mass index, LDL Low-density lipoprotein, HDL High-density lipoprotein, AST Aspartate aminotransferase, ALT Alanine aminotransferase. ${ }^{*} P<0.05$ when compared to the control group

$11.67 \pm 4.53$, respectively, with statistically significant differences under intergroup comparisons $(\mathrm{F}=44.493, P<$ 0.001) (Fig. 3c). On the contrary, the $D C$ and $C C$ values of the $\mathrm{CHC}$ and $\mathrm{CHB}$ group were significantly lower than those of the control group. The $\mathrm{DC}$ values of the three groups were $0.32 \pm 0.008,0.030 \pm 0.008$, and 0.017 $\pm 0.0081 / \mathrm{kPa}$, respectively (Fig. 3e), with statistically significant intergroup differences $(\mathrm{F}=3.897, P=0.021)$. The $C C$ values were $1.290 \pm 0.248,1.054 \pm 0.385$, and $0.815 \pm$ $0.378 \mathrm{~mm}^{2} / \mathrm{kPa}$, respectively (Fig. 3d), with statistically significant intergroup differences $(\mathrm{F}=29.717, \mathrm{P}<0.001)$. The DC and CC values of the $\mathrm{CHC}$ group were also significantly lower than those of the $\mathrm{CHB}$ group $(P<$ $0.001)$. Aix measurements showed no statistically significant differences among the 3 groups $(\mathrm{F}=2.237, P=$ 0.0109) (Fig. 3f).

\section{Comparison of liver stiffness and left common carotid elasticity parameters among different age groups}

All subjects were divided into two groups according to their age (Tables 2 and 3). with age 50 years being the dividing line. A comparison of the two groups showed no significant difference in ARFI values. However, in terms of carotid elasticity parameters, except for Aix, all other parameters including IMT, PWV, DC, CC, $\alpha$, and $\beta$ were significantly different between the two groups (all $P$ values $<0.001)$. In the $\mathrm{CHB}$ group, ARFI values, as well as parameters including IMT, PWV, DC, CC, $\alpha, \beta$, and Aix were all significantly different between the two age groups (all $P$ values $<0.05$ ). In the $\mathrm{CHC}$ group, IMT, PWV, DC, $\alpha, \beta$, and Aix were significantly different between the two age groups (all $P$ values $<0.05$ ).

\section{Relationship between liver stiffness with carotid artery elasticity in patients with chronic viral hepatitis}

Stepwise multiple linear regression analysis indicated that for patients with $\mathrm{CHB}$, age was an independent predictor of common carotid artery IMT $\left(R^{2}=0.468, F=\right.$ 54.635, and $P<0.001$ ) (Fig. 4a). For patients with $\mathrm{CHC}$, both age $(\beta=8.291, t=6.847, \mathrm{P}<0.001)$ and blood glucose $(\beta=22.436, t=2 / 573, P=0.012)$ were independent predictors of common carotid artery IMT $\left(\mathrm{R}^{2}=0.465, \mathrm{~F}=\right.$ 29.118, and $P<0.001$ ) (Fig. 4b, c).

\section{Discussions}

Chronic liver disease can cause abnormal lipid metabolism, which, in severe cases, can directly change the peripheral blood vessel walls. Timely and convenient measurements of changes in the peripheral blood vessel walls have a positive effect on preventing detrimental cardiovascular and cerebrovascular events $[1,8]$. Previous studies reported that $\mathrm{HCV}$ infection can alter in vivo glucose homeostasis and lipid metabolism leading to liver and peripheral insulin resistance $[9,10]$. Our study found that patients with $\mathrm{CHC}$ not only had thickened IMT compared to the control and the CHB groups, but also had higher PWV, $\alpha$, and $\beta$ parameters and lower DC and CC values than the control group. This 

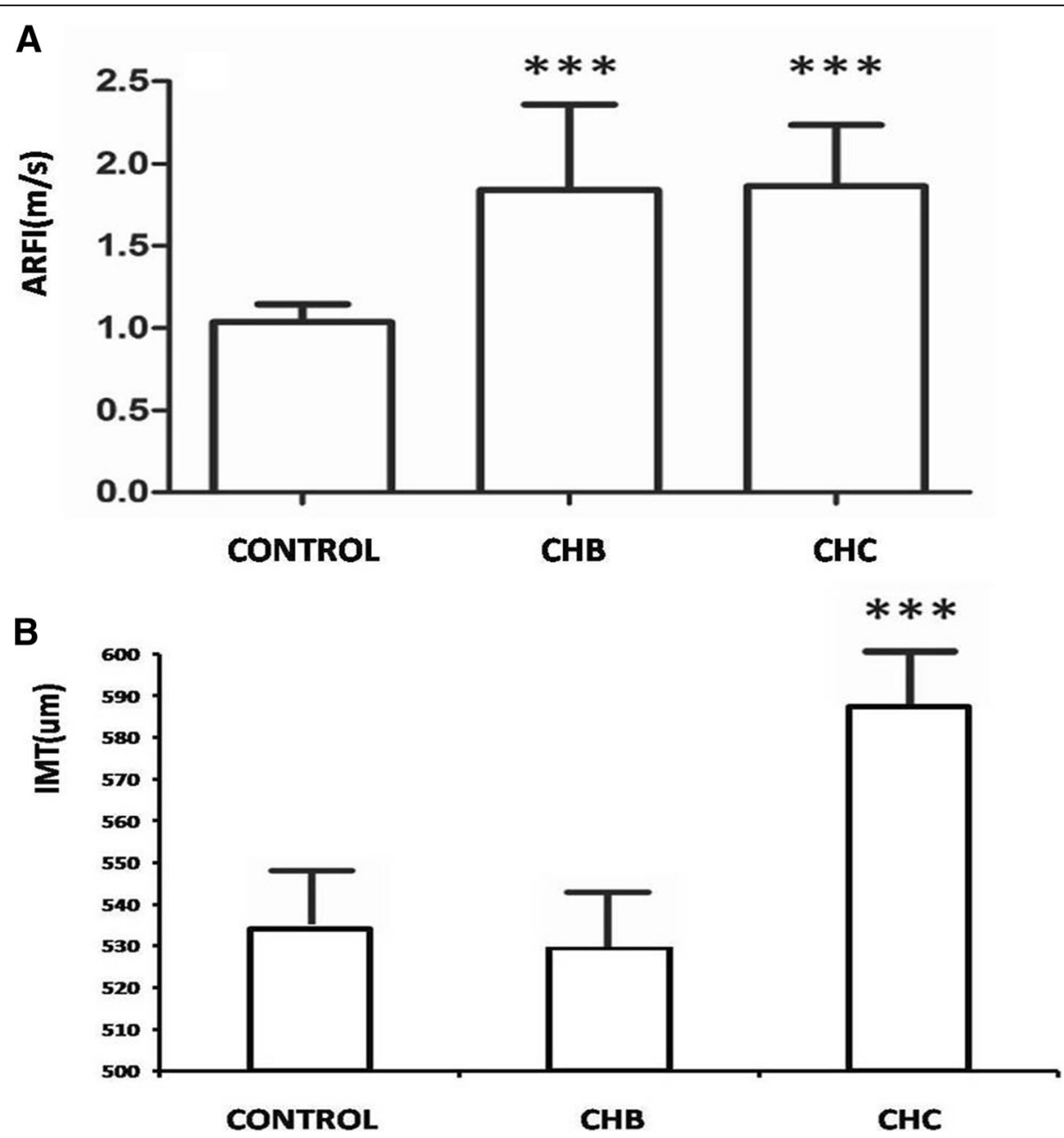

Fig. 2 Comparison of liver stiffness and carotid artery IMT values among the 3 groups: a Use of the ARFI technique to measure liver stiffness in patients with $\mathrm{CHB}, \mathrm{CHC}$ and control group using a conventional ultrasound interface. $\mathbf{b}$ Use of QIMT and QAS techniques to quantify the carotid artery intima-media thickness (IMT) and vascular elasticity in patients among the 3 groups. Note: ARFI: acoustic radiation force impulse; IMT: intima-media thickness; CHB: chronic hepatitis B; CHC: chronic hepatitis C; ${ }^{* *}$ : when compared to the control group, $P<0.001$

indicated that both the carotid artery structure and function parameters of the $\mathrm{CHC}$ group had changed compared to the control group. This finding was in line with the argument that HCV infection is a risk factor for atherosclerosis $[10,11]$. For patients with $\mathrm{CHB}$, although their carotid artery IMT were not thickened, their other parameters such as $\alpha$ and $\beta$ were higher, and their CC value was lower than those in the control group. These results indicated that, despite normal carotid artery wall structures, their carotid arteries and the elasticity parameters of their carotid artery walls had already changed. A possible explanation is that carotid atherosclerosis could cause both structural and functional changes. One major indicator for structural changes was an increase in the carotid IMT, while functional changes were mainly indicated by changes in carotid artery elasticity $[12,13]$. Although structural changes in the carotid artery can cause changes in its elasticity, such elasticity changes may also indicate that IMT thickening is not the only cause of arterial wall composition changes. It is speculated that carotid artery functional changes in patients with $\mathrm{CHB}$ may occur before the structural changes. Therefore, this study showed that patients with viral hepatitis maybe suffer a higher risk of cardiovascular events than healthy people, and this finding can provide some reference value for clinical diagnosis and treatment of these patients.

Age is also a critical factor affecting the potential for development of arteriosclerosis [14, 15]. In this study, participants were divided into two groups according to their age, with those aged 50 or above in one group and those aged under 50 in the other. It was found that within the CHB group, the ARFI value $(P=0.001)$ and the carotid artery elasticity parameters (all $P$ values < $0.05)$ differed significantly between the two age groups, indicating that these parameters might be related to the 

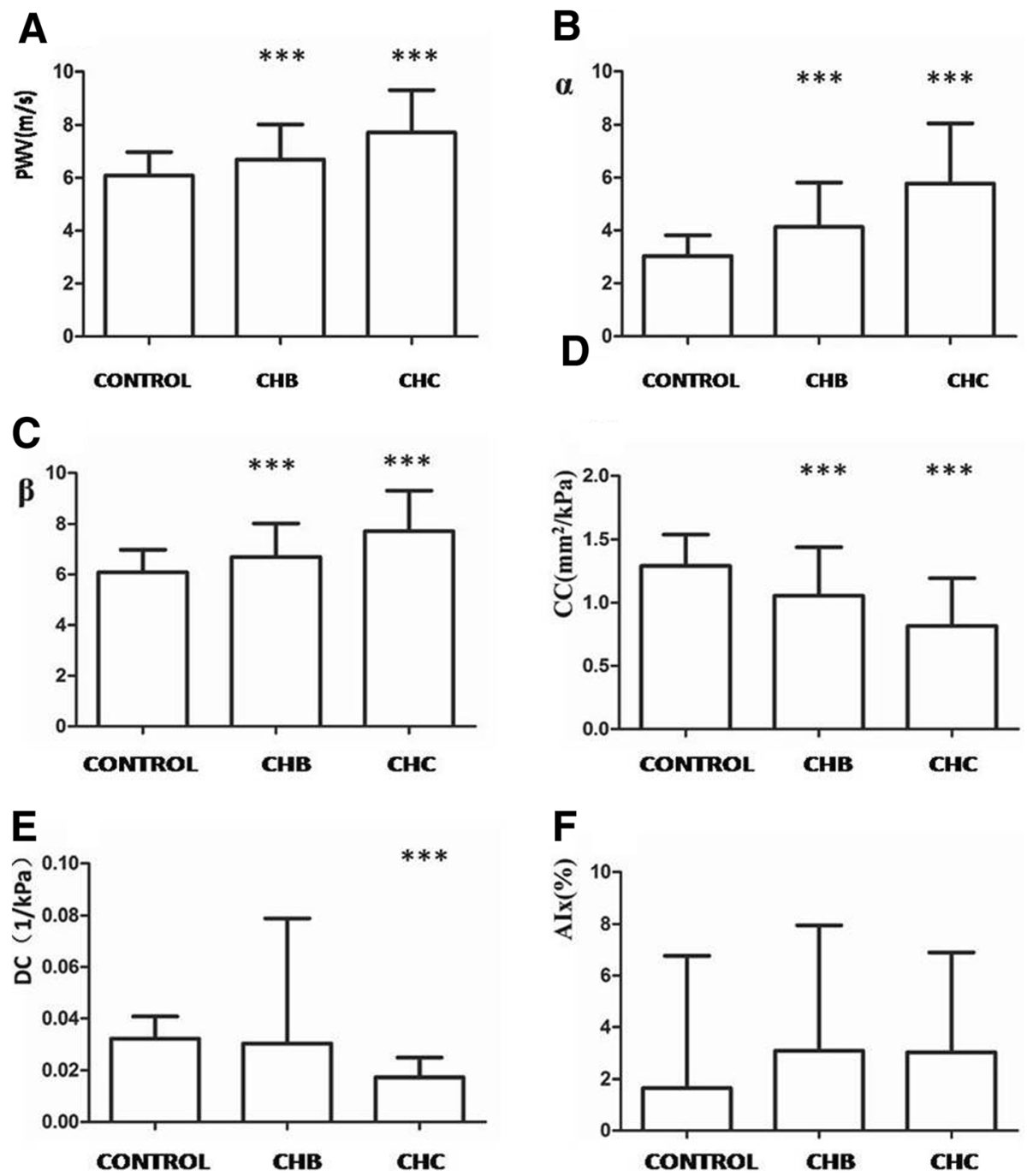

Fig. 3 Carotid elasticity parameters and comparisons among the 3 groups: a PWV values and comparisons among the 3 groups; $\mathbf{b}$ a values and comparisons among the 3 groups; $\mathbf{c} \beta$ values and comparisons among the 3 groups; $\mathbf{d}$ CC values and comparisons among the 3 groups; e DC values and comparisons among the 3 groups; $\mathbf{f}$ Aix values of the 3 groups. CHB: chronic hepatitis B; CHC: chronic hepatitis C; PWV: pulse wave velocity; CC: arterial wall compliance coefficient; DC: arterial wall dilation coefficient; Aix: augmentation index. Note: ${ }^{* * *}$ : when compared to the control group, $P<0.001$

Table 2 Liver stiffness and left common carotid elasticity parameters in the different age groups

\begin{tabular}{lllllll}
\hline & Age, Year & No. & ARFI, m/s & IMT, $\mu$ m & PWV, m/s & DC, $1 / \mathrm{kPa}$ \\
\hline Control Group & $<50$ & 41 & $1.02 \pm 0.09$ & $478.44 \pm 107.86$ & $5.72 \pm 0.73$ & $0.035 \pm 0.007$ \\
& $\geq 50$ & 23 & $1.06 \pm 0.13$ & $633.26 \pm 120.02$ & $6.75 \pm 0.80$ & $0.026 \pm 0.007$ \\
CHB Group & $P$ & - & 0.127 & $<0.001^{*}$ & $<0.001^{*}$ & $<0.001^{*}$ \\
& $<50$ & 86 & $1.72 \pm 0.50$ & $456.70 \pm 87.56$ & $6.26 \pm 1.35$ & $0.038 \pm 0.062$ \\
& $\geq 50$ & 61 & $2.02 \pm 0.50$ & $630.30 \pm 112.17$ & $7.32 \pm 1.00$ & $0.020 \pm 0.007$ \\
CHC Group & $P$ & - & $<0.001^{*}$ & $<0.001^{*}$ & $<0.001^{*}$ & $0.009^{*}$ \\
& $<50$ & 41 & $1.84 \pm 0.38$ & $526.63 \pm 130.03$ & $7.70 \pm 1.57$ & $0.018 \pm 0.009$ \\
& $\geq 50$ & 29 & $1.89 \pm 0.36$ & $673.17 \pm 167.48$ & $8.36 \pm 1.09$ & $0.015 \pm 0.006$ \\
\hline
\end{tabular}

$A R F I$ radio frequency, IMT intima-media thickness, $P W V$ pulse wave velocity, $D C$ arterial wall dilation coefficient ${ }^{*} P<0.05$ when compared to the control group 
Table 3 Liver stiffness and left common carotid elasticity parameters in the different age groups

\begin{tabular}{lllllll}
\hline & Age, Year & No. & CC, $\mathrm{mm}^{2} / \mathrm{kPa}$ & $a$ & $\beta$ & Aix, \\
\hline Control Group & $<50$ & 41 & $1.376 \pm 0.259$ & $2.70 \pm 0.54$ & $5.54 \pm 1.10$ & $0.82 \pm 5.18$ \\
& $\geq 50$ & 23 & $1.137 \pm 0.129$ & $3.63 \pm 0.81$ & $7.30 \pm 1.70$ & $3.14 \pm 4.76$ \\
& $P$ & - & $<0.001^{*}$ & $<0.001^{*}$ & $<0.001^{*}$ & 0.082 \\
CHB Group & 86 & $1.139 \pm 0.420$ & $3.71 \pm 1.69$ & $7.58 \pm 3.41$ & $1.55 \pm 4.41$ \\
& $\geq 50$ & 61 & $0.935 \pm 0.291$ & $4.72 \pm 1.51$ & $9.61 \pm 2.96$ & $5.25 \pm 4.68$ \\
& $P$ & - & $0.001^{*}$ & $<0.001^{*}$ & $<0.001^{*}$ & $<0.001^{*}$ \\
CHC Group & $<50$ & 41 & $0.854 \pm 0.423$ & $5.31 \pm 1.97$ & $10.65 \pm 3.79$ & $1.75 \pm 3.45$ \\
& $\geq 50$ & 29 & $0.761 \pm 0.303$ & $6.42 \pm 2.57$ & $13.11 \pm 5.13$ & $4.84 \pm 3.75$ \\
& $P$ & - & 0.317 & $0.044^{*}$ & $0.024^{*}$ & $0.001^{*}$ \\
\hline
\end{tabular}

CC arterial wall compliance coefficient, Aix augmentation index

* $P<0.05$ when compared to the control group

time span of HBV infection. Older patients with chronic hepatitis $\mathrm{B}$ are likely to carry the virus for a longer period of time and, consequently, experience a higher degree of liver stiffness. This difference was not observed in the control group, which indicated that aging is not related to the natural aging and fibrosis of the liver. In a study of 459 chronic HBV carriers, liver biopsies showed that the liver tissue inflammatory activity level and degree of liver fibrosis gradually increased with age [16], which was in line with our findings.

However, within the $\mathrm{CHC}$ group, the ARFI did not differ significantly between the two age groups $(P>0.05)$. A possible explanation was that patients with $\mathrm{CHC}$ have a higher risk of increased blood glucose levels. Studies on using the ARFI technique to grade liver stiffness and fibrosis showed that fat in the liver is an important factor that affects the accurate measurement of the ARFI value $[17,18]$. Since $40 \%$ of the patients with $\mathrm{CHC}$ in this study had elevated blood glucose, the abnormal lipid metabolism caused by abnormal blood sugar levels led to fat deposition in their liver, thus affecting the ARFI values. Although the accuracy of ARFI measurements were affected by abnormal blood glucose contents, measurements of carotid artery elasticity parameters were also found to be significantly abnormal. This indicated that HCV not only significantly affected liver stiffness but also changed carotid artery elasticity. Stepwise multiple linear regression analysis demonstrated that both
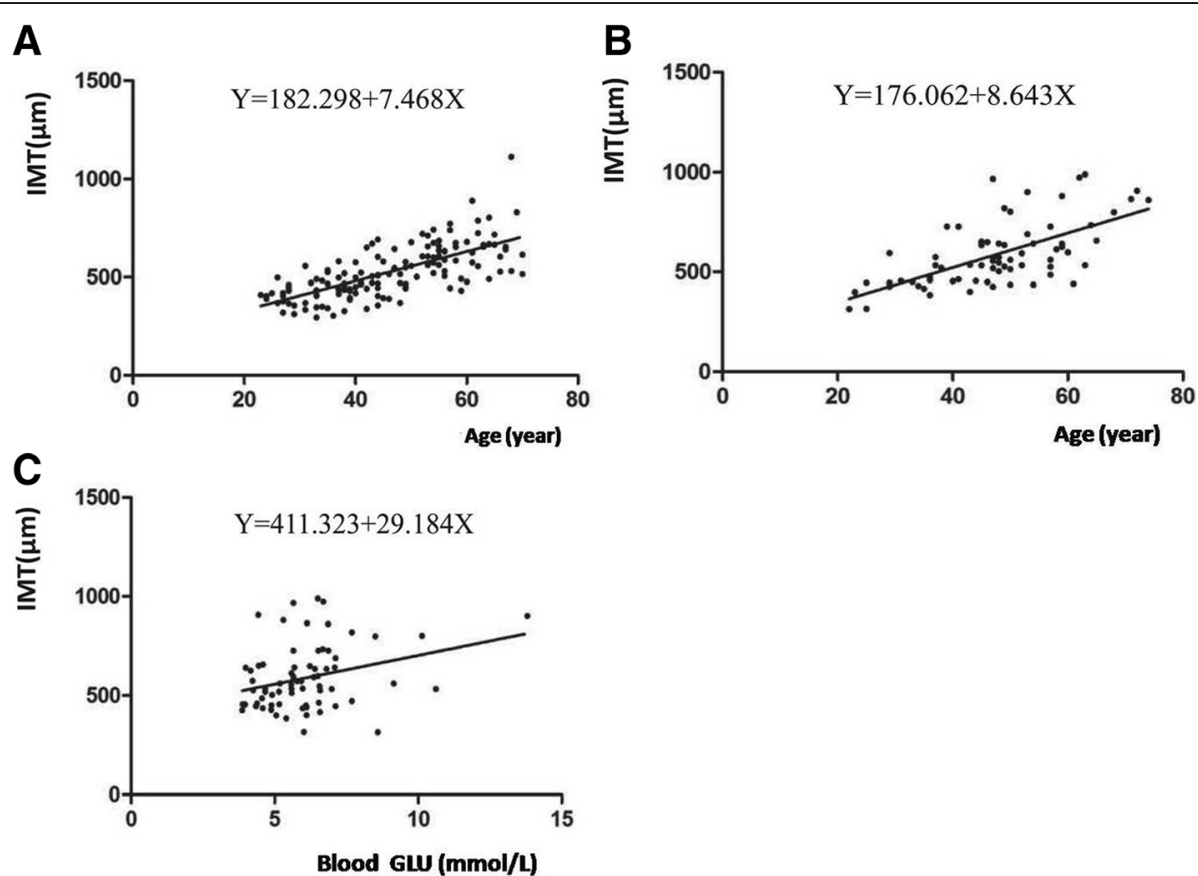

Fig. 4 a There was a relationship between IMT and age of CHB patients. b Relationship between IMT and age of CHC patients. c Relationship between IMT and blood glucose meter of CHC patients. Note: IMT: intima-media thickness; CHB: chronic hepatitis B; CHC: chronic hepatitis C 
age and blood sugar are independent predictors of IMT in patients with $\mathrm{CHC}$. Therefore, we speculated that, in addition to lipid metabolism, patients with chronic viral hepatitis also have metabolic syndromes caused by viral infections. The macrovascular damages caused by blood viscosity and hyperglycaemia also affect the structural changes of the carotid artery.

This study was limited by the fact that patients' diagnoses were made based on clinical diagnosis primarily. Biopsy was used to obtain pathological results in only a limited number of cases. The next step is to obtain results to classify liver fibrosis into different pathological levels, to further exclude any confounding factors.

\section{Conclusions}

In summary, using RF ultrasound and ARFI techniques to measure liver stiffness and carotid artery elasticity in patients with chronic viral hepatitis is beneficial for assessing the liver fibrosis and the structural and functional changes of the carotid artery. This serves as a reference for clinicians to monitor any vascular diseases in these patients.

\section{Abbreviations}

Aix: Augmentation index; ANOVA: Analysis of variance; ARFI: Acoustic radiation force impulse; CC: Compliance coefficient; CHB: Chronic hepatitis B; CHC: Chronic hepatitis C; DC: Arterial wall dilation coefficient; HBV: Hepatitis B virus; HCV: Hepatitis C virus; HCVAb: Hepatitis C virus antibody; IMT: Intimamedia thickness; PWV: Pulse wave velocity; RF: Radio frequency

\section{Acknowledgments}

We are grateful to the doctors and nurses working in Tangdu Hospital of Infectious diseases for the help in conducting of this study.

\section{Funding}

Project 81371566 supported by National Natural Science Foundation of China. The funders had no role in study design, data collection and analysis, decision to publish, or preparation of the manuscript

\section{Availability of data and materials}

The datasets used and analysed during the current study available from the corresponding author on reasonable request.

\begin{abstract}
Authors' contributions
YLY conceived the idea. YLY, NZ and JHL was responsible for conception and participation in design, experimental work and collection of data, analysis and interpretation of results, drifting and substantial editing the manuscript. BYM, XZS, YYD were responsible for experimental work and collection of data, analysis and interpretation of results. YLY was responsible for interpretation of results and critically revising the manuscript. All authors read and approved the final manuscript.
\end{abstract}

\section{Ethics approval and consent to participate}

This study was approved by the Ethics Committee of Tangdu Hospital (TDLL2013082) and written informed consent was obtained from the patients in our center.

\section{Consent for publication}

Not applicable.

\section{Competing interests}

The authors declare that they have no competing interests.

\section{Publisher's Note}

Springer Nature remains neutral with regard to jurisdictional claims in published maps and institutional affiliations.

Received: 6 April 2018 Accepted: 19 November 2018

Published online: 05 December 2018

\section{References}

1. Adinolfi LE, Zampino R, Restivo L, Lonardo A, Guerrera B, Marrone A, Nascimbeni F, Florio A, Loria P. Chronic hepatitis C virus infection and atherosclerosis: clinical impact and mechanisms [J]. World J Gastroenterol. 2014;20(13):3410-7.

2. Lorenz MW, Markus HS, Bots ML, Rosvall M, Sitzer M. Prediction of clinical cardiovascular events with carotid intima-media thickness: a systematic review and meta-analysis [J]. Circulation. 2007:115(4):459-67.

3. Castera L, Hepatitis B. Are non-invasive markers of liver fibrosis reliable?[ J]. Liver Int. 2014;34:91-6.

4. Wang $Y$, Duan $Y Y$, Zhang $L, Y$ uan $L J, X u L$. The predictive value of carotid intima-media thickness and elasticity for coronary heart disease[J]. Chin J med ultrasound. 2013;10(9):39-45.

5. Wei L, Hou JL. Guideline of chronic hepatitis B prevention (2015 version) [J]. Infect Dis Info. 2015:28(6):321-40.

6. Ferraioli G, Filice C, Castera L, Choi BI, Sporea I, Wilson SR, Cosgrove D, Dietrich CF, Amy D, Bamber JC, Barr R, Chou YH, Ding H, Farrokh A, Friedrich-Rust M, Hall TJ, Nakashima K, Nightingale KR, Palmeri ML, Schafer F, Shiina T, Suzuki S, Guidelines KMWFUMB. Recommendations for clinical use of ultrasound Elastography: part 3: liver [J]. ultrasound in. Medicine and Biology. 2015:41(5):1161-79.

7. Zhang L, Yin JK, Duan YY, Liu X, Xu L. Evaluation of carotid artery elasticity changes in patients with type 2 diabetes [J]. Cardiovasc Diabetol. 2014;13:39-45.

8. Li WC, Lee YY, Chen IC, Sun C, Chiu FH, Chuang CH. Association between the hepatitis $B$ and $C$ viruses and metabolic diseases in patients stratified by age [J]. Liver Int. 2013;33(8):1194-202.

9. Adinolfi LE, Restivo L, Zampino R, Guerrera B, Lonardo A, Ruggiero L, Riello F, Loria P. Florio A. Chronic HCV infection is a risk of atherosclerosis. Role of HCV and HCV-related steatosis [J]. Atherosclerosis. 2012;221(2):496-502.

10. Ishizaka N, Ishizaka Y, Takahashi E, Toda Ei E, Hashimoto H, Ohno M, Nagai $\mathrm{R}$, Yamakado M. Increased prevalence of carotid atherosclerosis in hepatitis B virus carriers [J]. Circulation. 2002;105(9):1028-30.

11. Ishizaka N, Ishizaka Y, Takahashi E, Ei T, Hashimoto H, Nagai R, Yamakado M. association between hepatitis $C$ virus seropositivity, carotid-artery plaque, and intima-media thickening [J]. Lancet. 2002;359(9301):133-5.

12. Patel AK, Suri HS, Singh J, Kumar D, Shafique S, Nicolaides A, Jain SK, Saba L, Gupta A, Laird JR, Giannopoulos A, Suri JSA. Review on atherosclerotic biology, wall stiffness, physics of elasticity, and its ultrasound-based measurement[J]. Curr Atheroscler Rep. 2016;18(12):83-92.

13. Boesen ME, Singh D, Menon BK, Frayne R. a systematic literature review of the effect of carotid atherosclerosis on local vessel stiffness and elasticity[J]. Atherosclerosis. 2015;243(1):211-22.

14. Pelisek J, Wendorff H, Wendorff C, Kuehnl A, Eckstein HH. Age-associated changes in human carotid atherosclerotic plaques[J]. Ann Med. 2016;48(7): 541-51.

15. Maloberti A, Meani P, Varrenti M, Giupponi L, Stucchi M, Vallerio P, Structural GC. Functional abnormalities of carotid artery and their relation with EVA phenomenon[J]. High Blood Press Cardiovasc Prev. 2015;22(4):373-9.

16. Xing YF, Tong GD, Zhou DQ, He JS, Shao MM, Wei CS, Chen YJ. Liver histological features analysis of 459 cases chronic hepatitis B virus carriers[J]. Chinese Journal of Integrated Traditional and Western Medicine on Liver Diseases. 2015:6:324-7.

17. Karlas T, Petroff D, Sasso M, Fan JG, Mi YQ, de Lédinghen V, Kumar M, Lupsor-Platon M, Han KH, Cardoso AC, Ferraioli G, Chan WK, Wong WW Myers RP, Chayama K, Friedrich-Rust M, Beaugrand M, Shen F, Hiriart JB, Sarin SK, Badea R, Lee HW, Marcellin P, Filice C, Mahadeva S, Wong GL, Crotty P, Masaki K, Bojunga J, Bedossa P, Keim V, Wiegand J. Impact of controlled attenuation parameter on detecting fibrosis using liver stiffness measurement[J]. Aliment Pharmacol Ther. 2018:15:1-12.

18. Kelly ML, Riordan SM, Bopage R, Lloyd AR, Post JJ. Capacity of non-invasive hepatic fibrosis algorithms to replace transient elastography to exclude cirrhosis in people with hepatitis C virus infection: a multi-Centre observational study[J]. PLoS One. 2018;13(2):e0192763. 